\title{
NUMERICAL ASSESSMENT ON THE SEISMIC RESPONSE OF A BASE-ISOLATED BUILDING UNDER BI-DIRECTIONAL MOTION
}

\author{
M. Furinghetti ${ }^{1}$, A. Pavese $^{2}$ \\ ${ }^{1}$ UME School - Pavia \\ via Ferrata 1, 27100 Pavia - Italy \\ e-mail: marco.furinghetti@umeschool.it \\ ${ }^{2}$ University of Pavia \\ via Ferrata 3, 27100 Pavia - Italy \\ e-mail: a.pavese@unipv.it
}

Keywords: Concave Sliding Surface device, Bi-Directional motion, cycling effect, friction coefficient, heating phenomena.

\begin{abstract}
Experimental and analytical studies on Concave Sliding Surface devices have underlined that the hysteretic characteristics under bi-directional input motion are highly nonlinear, in comparison with the uni-directional case. The force response of the device along both directions of motion strongly depend on the shape of the trajectory, because of the stepwise changing of direction of the frictional force, rather than in a uni-directional motion in which all forces have the same direction. Together with these aspects, also the variation of the frictional properties with respect to sliding velocity (Velocity Effect), vertical load (Vertical Load Effect) and heating phenomena originated at the sliding interfaces (Cycling Effect) increase the non-linearity of the behavior of such kind of isolators, leading to dispersions of the peak quantities when time history analyses are performed: such dispersions can not be neglected a priori, but they have to be accurately evaluated. In addition, experimental tests have shown widely sparse frictional properties of the sliding materials commonly used for CSS devices, even when the same conditions of loading are considered. Moreover, in real applications, the spatial distribution of both the devices and the isolated building affect the overall response, especially when irregularities in the installation of the isolators are considered, which results into uneven inclinations of the sliding surfaces with respect to the horizontal plane. In this endeavor a wide numerical campaign has been carried out on a case study, considering several layout conditions, the actual dispersion of the frictional characteristics of the device, and different models of the friction coefficient for all the isolators. The results of all the numerical simulations, performed by means of time history analyses, have allowed to underline some important aspects which must be accounted for when designing a structural system, isolated using a grid of CSS devices, under bi-directional seismic excitations.
\end{abstract}




\section{INTRODUCTION}

A growing interest toward the response assessment of friction based devices has been observed during the last years both using numerical and experimental approaches $[6,7,10,13]$. In the experimental field both Single and Double Curved Surface Slider devices (SCSS and DCSS) have been investigated in some details, in order to evaluate the overall features giving important indications on how such devices have to be modeled. In a previous study Lomiento et al. analyzed the frictional behavior of CSS devices subjected to bidirectional motions, in terms of dependency of the friction coefficient with respect to the sliding velocity (velocity effect) and to the applied vertical load (load effect) [4]. Moreover, due to the heating phenomena occurring at the sliding interfaces, it has been observed that the friction coefficient decreases under long lasting cyclic motions $[4,5]$ (cycling effect). A wide testing campaign was carried out on a DCSS device by Furinghetti et al.: results showed that the friction decay caused by the cycling effect assumes a decreasing exponential trend with respect to the dissipated energy, regardless the shape of the trajectory that the device is subjected to (Figure 1) [3]. A number of different trajectories were considered, among which the bidirectional cloverleaf ruled by the standard code UNI:EN15129:2009 [7].

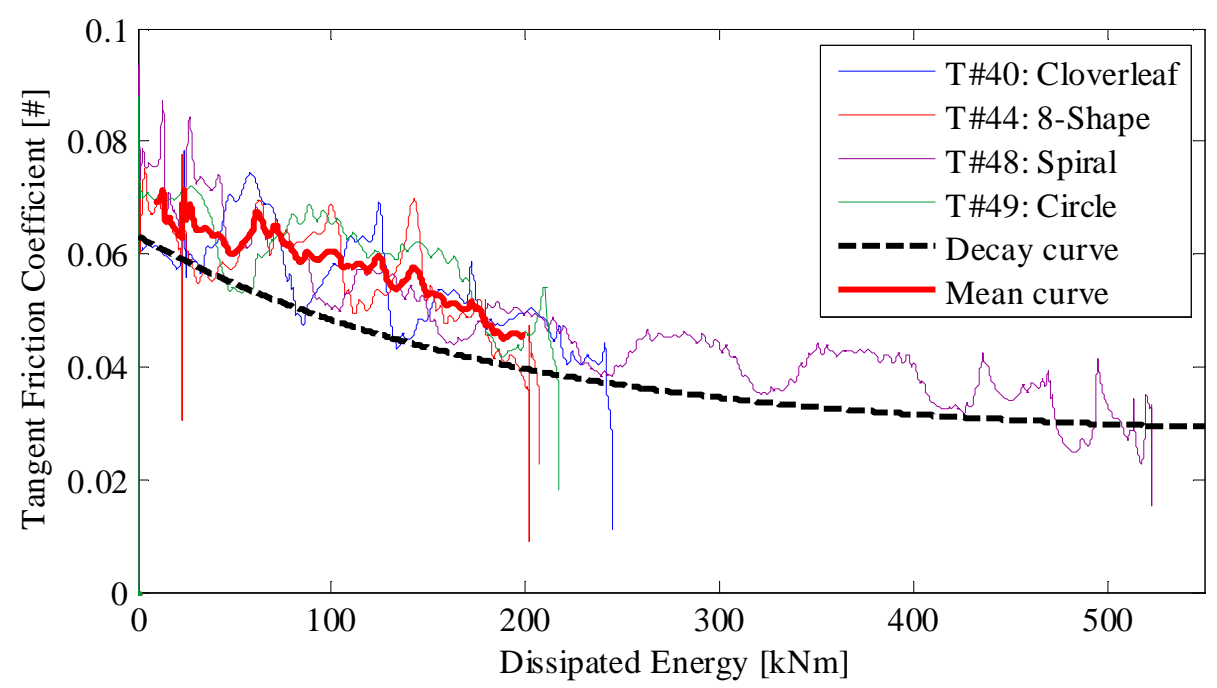

Figure 1: Frictional decay due to cyclic bidirectional loading [3].

Additional fluctuations were found, which could be originated by uneven rotations of the internal non-articulated slider, rather than oscillation of the vertical load. This behavior is supposed to significantly influence the overall response of a structural system isolated by means of CSS devices.

In the present study a wide numerical assessment is presented, aiming at evaluating the direct effects of the cycling loading on the response of a multy-storey building isolated with DCSS devices. An ad hoc mass-independent dynamic system has been directly defined, which allows to carry out parametric studies, considering an actual non-linear constitutive law for the isolation system, accounting for bi-axial interaction of the frictional force along the main directions of motion. The scope of this work is to highlight the influence of the cycling effect on the main response quantities, in terms of peak displacements, absolute accelerations and interstorey shears. Results show that accounting for the cycling effect leads to non-negligible variation of all the response parameters with respect to the reference case, in which no friction coefficient decay is considered. 


\section{MECHANICAL MODEL OF THE DEVICES}

The structural system has been seismically isolated using Double Concave Sliding Surface devices (DCSS) with a non-articulated slider: such devices, shown in Figure 2, have the same characteristics as the one described in a previous work [3].

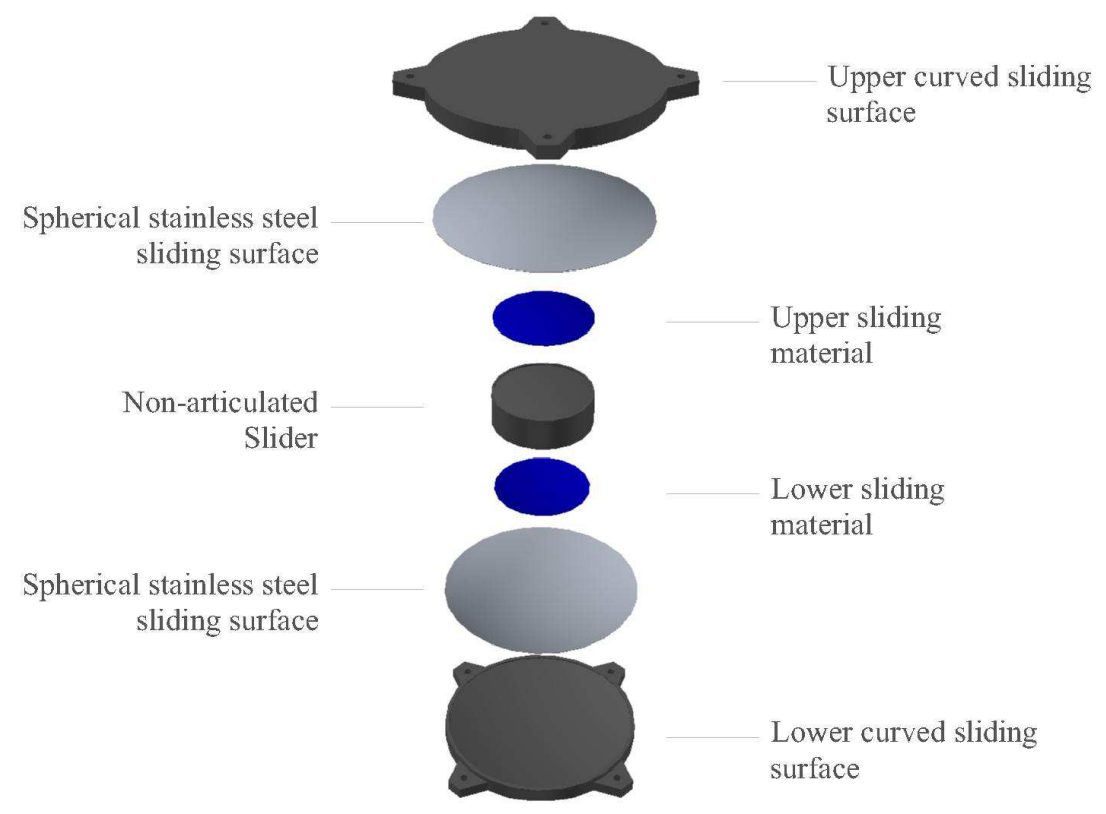

Figure 2: Components of the device.

The curvature radius for both the sliding surfaces is equal to $1,6 \mathrm{~m}$ and the height of the internal slider is $0,1 \mathrm{~m}$ : these geometric quantities imply that the equivalent radius of curvature of the whole device is equal to $3,1 \mathrm{~m}[10]$.

The mechanical model of the device has been considered as the summation of two contributions (eq.(1)).

$$
F_{\text {device }}=F_{r}+F_{f}
$$

The former is represented by the restoring force $\mathrm{F}_{\mathrm{r}}$ (eq.(2)) caused by the projection of the vertical load applied to the device along the curved sliding surfaces [2]: the restoring behavior can be modeled using a linear spring with respect to the displacements along both $\mathrm{x}$ and $\mathrm{y}$ directions, with a stiffness coefficient given by the ratio between the vertical load $\mathrm{W}$ and the equivalent radius of curvature $R_{\text {eq }}[2]$.

$$
F_{r}=\frac{W}{R_{e q}} \cdot\left[\begin{array}{l}
u_{0, x} \\
u_{0, y}
\end{array}\right]
$$

The latter contribution consists of the frictional force $F_{f}$ due to the sliding movements at both the upper and the lower curved surfaces (eq.(3)). The same model presented in a previous study has been used, thus assuming the total frictional force, returned by the product between the friction coefficient and the vertical load, aligned with respect to the tangent line to the trajectory of the device: hence, such a force has been stepwise projected along the main directions of motion $\mathrm{x}$ and $\mathrm{y}$. The friction coefficient can be considered as a function of vertical load (load effect), sliding velocity (velocity effect) and the dissipated energy (cycling effect) $[5,8]$. 


$$
F_{f}=\mu(W, v, E) \cdot W \cdot \tanh \left(\frac{v}{v_{s}}\right) \cdot\left[\begin{array}{l}
\frac{\dot{u}_{0, x}}{\sqrt{\left(\dot{u}_{0, x}\right)^{2}+\left(\dot{u}_{0, y}\right)^{2}}} \\
\frac{\dot{u}_{0, y}}{\sqrt{\left(\dot{u}_{0, x}\right)^{2}+\left(\dot{u}_{0, y}\right)^{2}}}
\end{array}\right]
$$

The parameter which rules the transition through the "zero velocity point" $\mathrm{v}_{\mathrm{s}}$ has been assumed equal to $0,0075 \mathrm{~m} / \mathrm{s}$.

In this endeavor the friction coefficient has been assumed as a function of the dissipated energy only, in order to underline the direct consequences of the cycling effect on the main response quantities of the whole structural system. In a previous experimental campaign carried out on a full scale device at EUCENTRE TREES Lab in Pavia $[3,12]$ results have shown that the friction coefficient decreases with respect to the dissipated energy with an exponential trend, considering both unidirectional and bidirectional motions. According to the aforementioned evidence, in this work the same multiplication factor which rules the exponential decay of the friction coefficient caused by the cycling effect has been implemented, as shown in eq.(4).

$$
\mu(W, v, E)=\mu(W, v) \cdot k_{E}=\bar{\mu} \cdot\left[a \cdot e^{-b \cdot E}+c\right]
$$

The numerical values of the parameters of the exponential curve $a, b$ and $c$ are the same returned by the non-linear fitting procedure reported in Furinghetti et al. 2014 [3]; moreover the $\mathrm{b}$ value, the parameter which affects the hardness of the friction coefficient decay, has been assumed as uniformly distributed in a range between $\pm 100 \%$ of the mean value: all the parameters of the device are listed in Table 1.

\begin{tabular}{ll}
\hline Parameter & Value \\
\hline $\bar{\mu}$ & 0,0500 \\
$\mathrm{a}$ & 0,5675 \\
$\mathrm{~b}$ & $0,0050( \pm 100 \%)$ \\
$\mathrm{c}$ & 0,4325 \\
$\mathrm{R}_{\mathrm{eq}}$ & $3,1 \mathrm{~m}$ \\
\hline
\end{tabular}

Table 1: Parameters of the mechanical model.

In Figure 3 some decay curves randomly extracted by the uniform numerical simulator are shown.

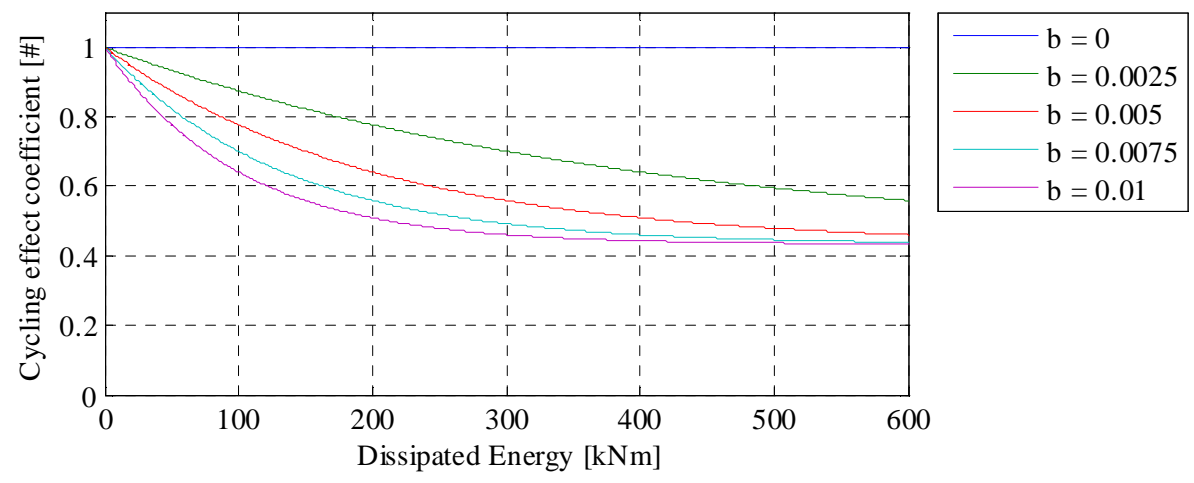

Figure 3: Friction Coefficient decay curves. 


\section{NUMERICAL MODEL OF THE DYNAMIC SYSTEM}

In this paper a new formulation of the dynamic system of a building seismically isolated by means of DCSS devices is presented.

\subsection{Modeling of the building}

The building has been modeled as a shear type MDOF system, having the same period in both $\mathrm{x}$ and y directions; actually, the same mass and the same translational stiffness has been considered for each floor [11]. Moreover, no torsional stiffness has been assumed for all floors. Thus, given the total number of stories $\mathrm{N}_{\mathrm{F}}$ :

$$
\begin{aligned}
& m_{1}=m_{2}=m_{3}=\ldots=m_{N_{F}}=m \\
& k_{1}=k_{2}=k_{3}=\ldots=k_{N_{F}}=k
\end{aligned}
$$

According to this assumption (eq.(5)), it is possible to introduce a "fictitious period" value (eq.(6)) which refers to the values of mass and stiffness of a single storey of the building, as follows:

$$
T_{s}^{*}=\frac{2 \pi}{\omega_{s}^{*}}=2 \pi \sqrt{\frac{m}{k}}
$$

This definition is very useful, since the final scope is to define the dynamic system of the building, normalized with respect to the mass of a single storey. Moreover, for a given number of stories, a linear relationship between the period of the first mode of the building (considered fixed at the base) and the just defined fictitious period has been detected, as shown in Figure 4: it can be noted that as the number of floors increases, the proportional coefficient between the fictitious period and the $1^{\text {st }}$ mode period increases.

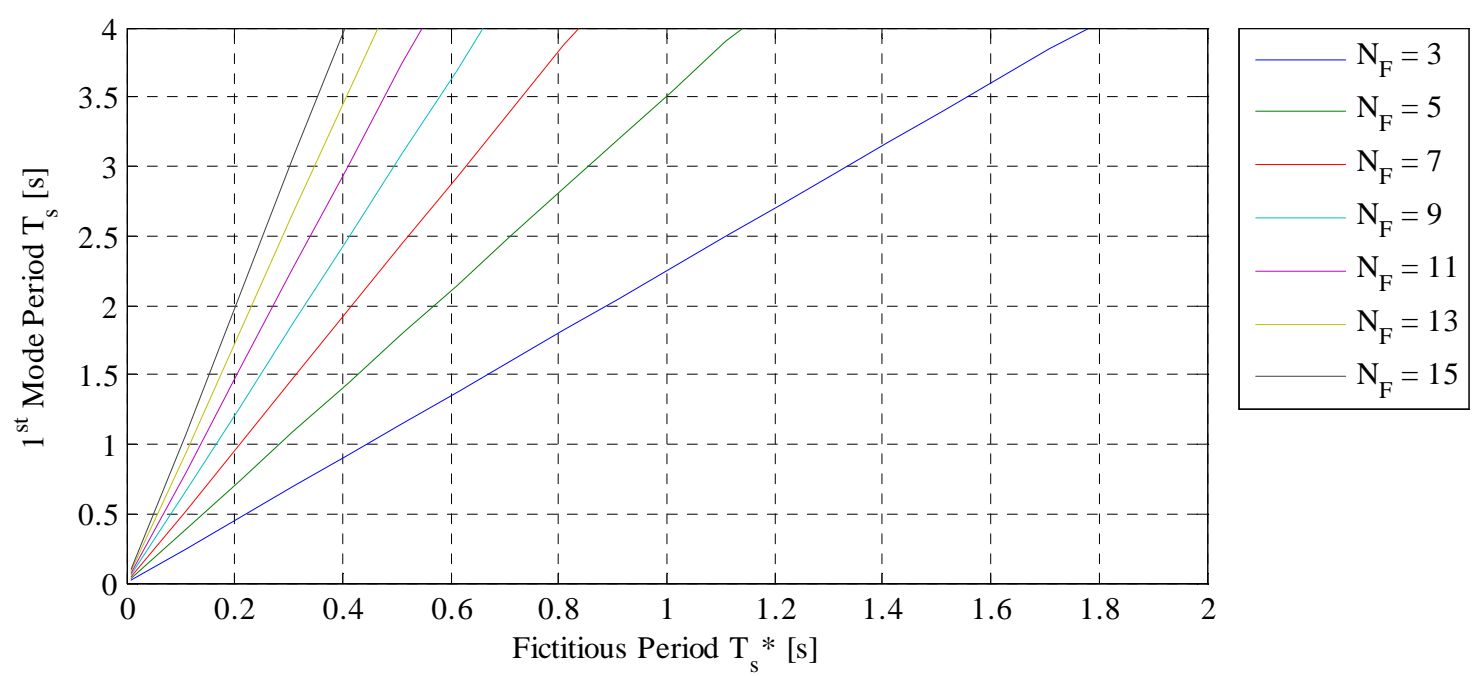

Figure 4: Linear relationship between the $1^{\text {st }}$ mode period and the fictitious period.

Hence, considering the building "fixed at the base", the normalized mass and stiffness matrices for both $\mathrm{x}$ and $\mathrm{y}$ directions are an identity matrix and a shear-type stiffness matrix respectively (eq.(7)). 


$$
\begin{aligned}
\frac{M_{B}}{m} & =\left[\begin{array}{cccc}
1 & 0 & \cdots & 0 \\
0 & 1 & \ddots & \vdots \\
\vdots & \ddots & \ddots & 0 \\
0 & \ldots & 0 & 1
\end{array}\right] \\
\frac{K_{B}}{m} & =\left[\begin{array}{cccc}
2 & -1 & & 0 \\
-1 & \ddots & \ddots & \\
& \ddots & 2 & -1 \\
0 & & -1 & 1
\end{array}\right] \cdot \omega_{s}^{* 2}
\end{aligned}
$$

For such a system, Rayleigh damping has been considered only for the building [11] (eq.(8)). Considering the fixed periods of all the unidirectional modes of the building, and according to the common definition of the damping matrix of the system, the proportional coefficients have been computed using a least-squares procedure and considering $5 \%$ of damping ratio for all the modes.

$$
\frac{C_{B}}{m}=a_{0} \frac{M_{B}}{m}+a_{1} \frac{K_{B}}{m}
$$

In Figure 5 results of an example for a five storey building having the $1^{\text {st }}$ mode "fixed" period equal to $1,0 \mathrm{sec}$ are reported.

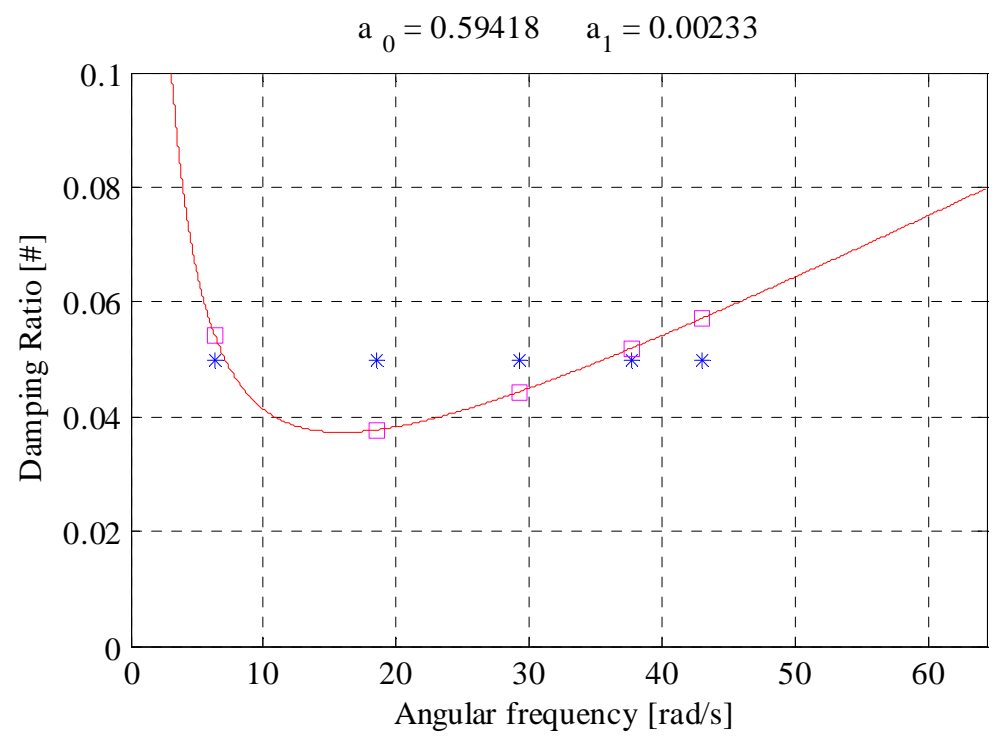

Figure 5: Least-squares procedure to determine Rayleigh Damping parameters.

In order to check the efficiency of such a model for the damping, a fixed-base building has been analyzed, when subjected to a double-impulsive acceleration time-history, which corresponds to a displacement step function (Figure 6) aiming at analyzing the response of the building under free-damped oscillations. 

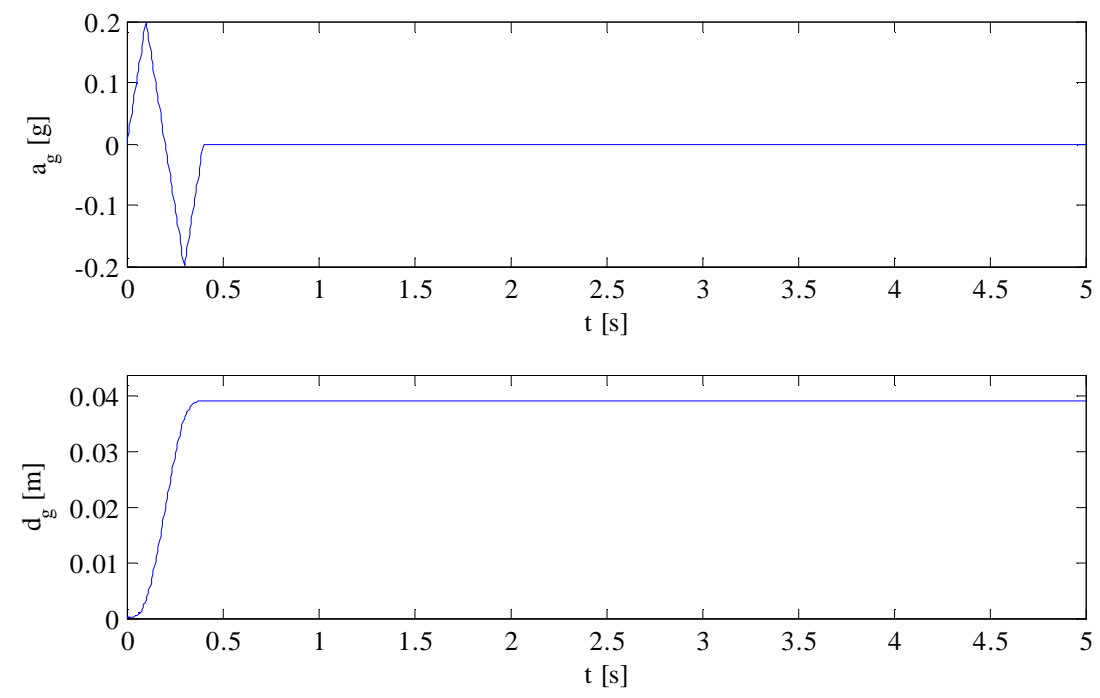

Figure 6: Input signal for the damping ratio check.

For all the stories, the exponential decay of the displacement due to damping has been checked, according to the assumed damping ratio (5\%). In Figure 7 results are shown.
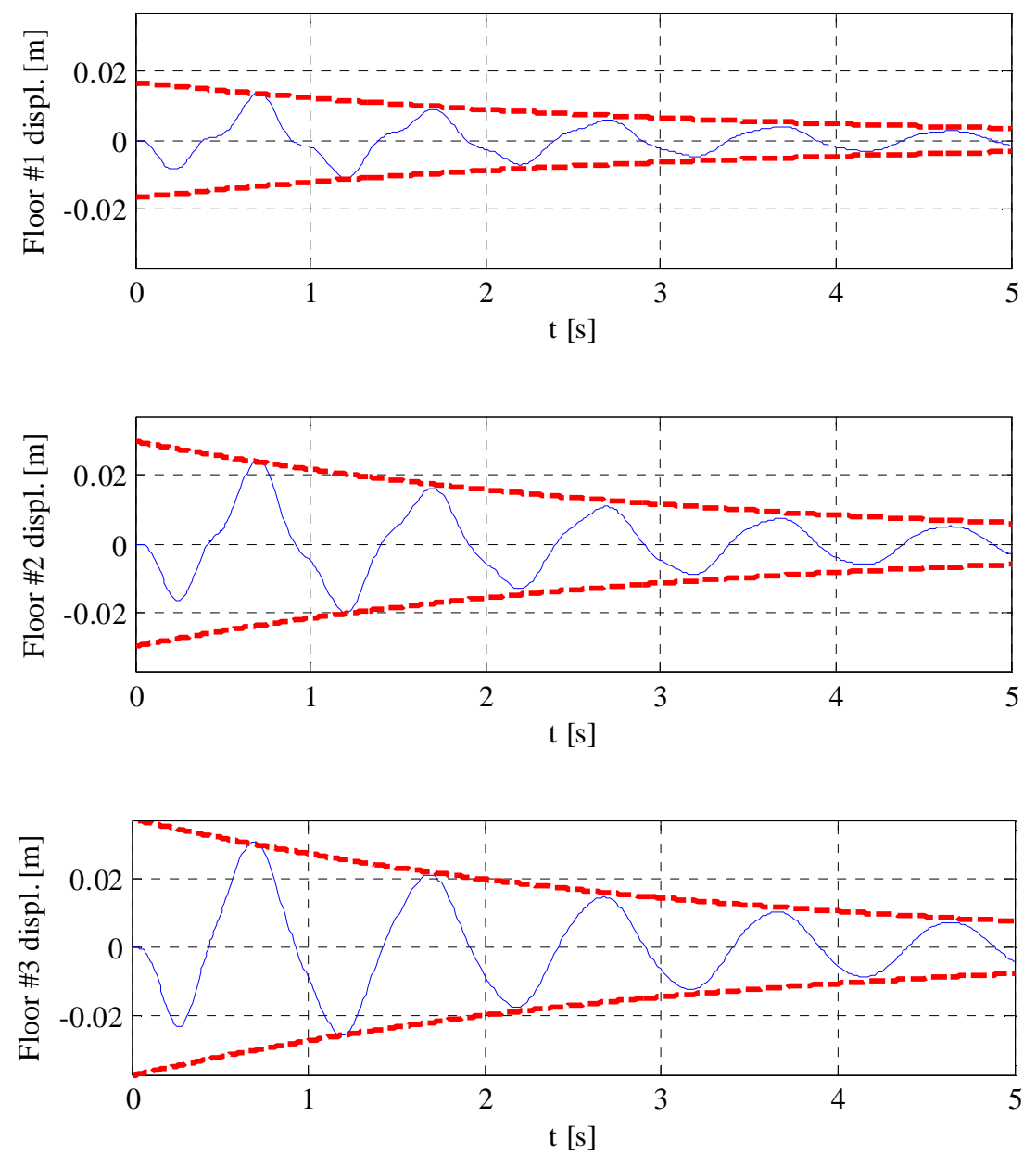

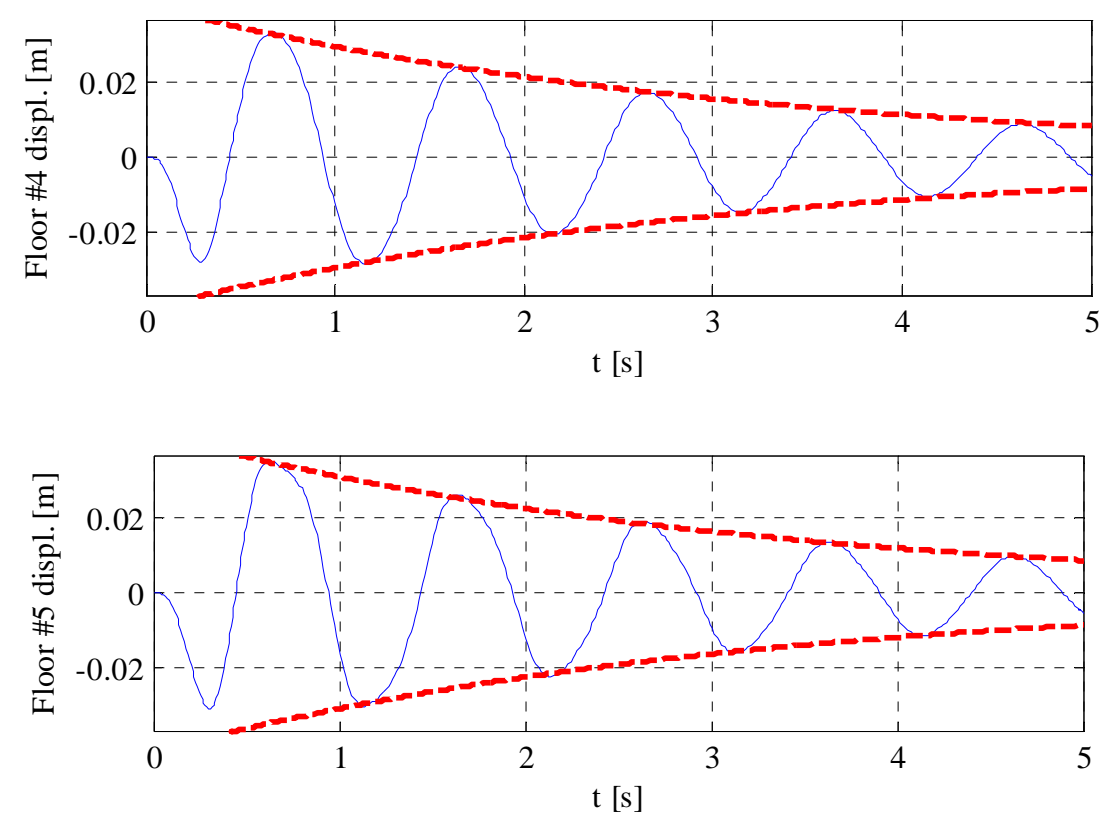

Figure 7: Displacement decay check under free-damped vibrations.

It can be noted that the theoretical exponential decay reflects the actual response of the building at each floor.

\subsection{Modeling of the base-isolated system}

The full model of the isolated structure consists of a MDOF model for both $\mathrm{x}$ and $\mathrm{y}$ directions: the first mass represents the isolated plate laid on the isolation system, whereas the others are the masses of each floor of the building. In Figure 8 all the considered degrees of freedom are shown.
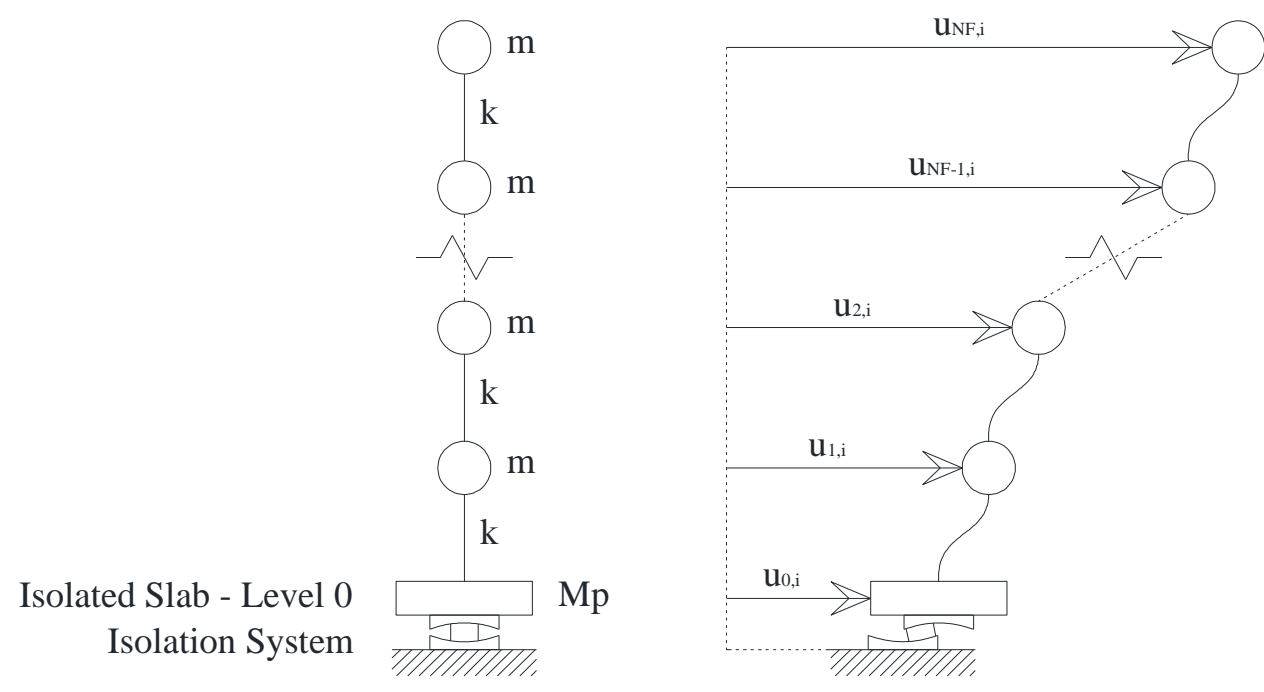

i-th direction

Figure 8: Dynamic model of the isolated structure. 
Thus, according to Figure 8, the normalized mass and stiffness matrices can be written as shown in eq.(9):

$$
\begin{aligned}
& \frac{M_{t o t}}{m}=\frac{1}{m} \cdot\left[\begin{array}{c:cccc}
M_{p} & 0 & 0 & \cdots & 0 \\
\hdashline 0 & m & 0 & \cdots & 0 \\
0 & 0 & m & \ddots & \vdots \\
\vdots & \vdots & \ddots & \ddots & 0 \\
0 & 0 & \cdots & 0 & m
\end{array}\right]=\left[\begin{array}{c:cccc}
N_{F} / r & 0 & 0 & \cdots & 0 \\
\hdashline 0 & 1 & 0 & \cdots & 0 \\
0 & 0 & 1 & \ddots & \vdots \\
\vdots & \vdots & \ddots & \ddots & 0 \\
0 & 0 & \cdots & 0 & 1
\end{array}\right] \\
& \frac{K_{t o t}}{m}=\left[\begin{array}{c:cccc}
1 & -1 & 0 & \cdots & 0 \\
\hdashline-1 & 2 & -1 & & 0 \\
0 & -1 & \ddots & \ddots & \\
\vdots & & \ddots & 2 & -1 \\
0 & 0 & & -1 & 1
\end{array}\right] \cdot \frac{k}{m}=\left[\begin{array}{c:cccc}
1 & -1 & 0 & \cdots & 0 \\
\hdashline-1 & 2 & -1 & 0 \\
0 & -1 & \ddots & \ddots & \\
\vdots & & \ddots & 2 & -1 \\
0 & 0 & & -1 & 1
\end{array}\right] \cdot \omega_{s}^{* 2}
\end{aligned}
$$

Where $r$ is the ratio between the mass of the whole building and the mass of the isolated slab. The normalized damping matrix is obtained in eq.(10) using the Rayleigh formulation, assuming the coefficients $\mathrm{a}_{0}$ and $\mathrm{a}_{1}$ previously described, considering the building fixed at the base.

$$
\frac{C_{t o t}}{m}=a_{0} \frac{M_{t o t}}{m}+a_{1} \frac{K_{t o t}}{m}
$$

Concerning the isolation system, when a building with a large plan development is considered, it is possible to consider one equivalent device, having a constitutive law which is representative for the entire isolation system. Thus, according to this assumption, all the isolators have averagely the same vertical load, directly equal to the total weight of the isolated structure divided by the number of devices; the value of vertical load of the single device has been fundamental for the computation of the dissipated energy and, consequently, to account for the friction coefficient decay due to the cycling effect, since the calibrated model refers to a single full scale device [3]. Hence, the horizontal force along both $\mathrm{x}$ and $\mathrm{y}$ directions of the isolation system can be computed as shown in eq.(11):

$$
\frac{F_{i s}}{m}=g \cdot N_{F} \cdot\left(1+\frac{1}{r}\right) \cdot\left\{\frac{1}{R_{e q}}\left[\begin{array}{l}
u_{0, x} \\
u_{0, y}
\end{array}\right]+\mu(W, v, E) \cdot \tanh \left(\frac{v}{v_{s}}\right) \cdot\left[\begin{array}{c}
\frac{\dot{u}_{0, x}}{\sqrt{\left(\dot{u}_{0, x}\right)^{2}+\left(\dot{u}_{0, y}\right)^{2}}} \\
\left.\frac{\dot{u}_{0, y}}{\sqrt{\left(\dot{u}_{0, x}\right)^{2}+\left(\dot{u}_{0, y}\right)^{2}}}\right]
\end{array}\right\}\right.
$$

being

$$
\frac{W_{t o t}}{m}=\frac{g}{m} \cdot\left(M_{B}+M_{P}\right)=\frac{g}{m} \cdot M_{B} \cdot\left(1+\frac{M_{P}}{M_{B}}\right)=\frac{g}{m} \cdot M_{B} \cdot\left(1+\frac{1}{r}\right)=g \cdot N_{F} \cdot\left(1+\frac{1}{r}\right)
$$

Finally, the normalized dynamic system of the isolated structure can be defined for direction $\mathrm{i}=\mathrm{x}, \mathrm{y}$ (eq.(12)). The contribution of the isolation system has to be added only in the first equation for both directions, that is the translational dynamic equilibrium of the isolated slab. 


$$
\left[\frac{M_{t o t}}{m}\right]\left(\begin{array}{c}
\ddot{u}_{0, i} \\
\ddot{\ddot{u}}_{1, i}^{-} \\
\ddot{u}_{2, i} \\
\vdots \\
\ddot{u}_{N_{F}, i}
\end{array}\right)+\left[\frac{C_{t o t}}{m}\right]\left(\begin{array}{c}
0 \\
-\dot{u}_{1, i}-\dot{u}_{0, i} \\
\dot{u}_{2, i}-\dot{u}_{0, i} \\
\vdots \\
\dot{u}_{N_{F}, i}-\dot{u}_{0, i}
\end{array}\right)+\left[\frac{K_{t o t}}{m}\right]\left(\begin{array}{c}
u_{0, i} \\
-u_{1, i} \\
u_{2, i} \\
\vdots \\
u_{N_{F}, i}
\end{array}\right)+\frac{F_{i s, i}}{m}\left(\begin{array}{c}
\frac{1}{0} \\
0 \\
\vdots \\
0
\end{array}\right)=-\left[\frac{M_{t o t}}{m}\right] \cdot \ddot{u}_{g, i}
$$

It can be noted that the normalized damping matrix has been multiplied by the vector of relative velocities with respect to the isolated slab: in fact, the damping has to influence the response of the building relatively to its base, that is the isolated slab; whereas the isolated slab response is affected by the hysteretic damping due to the non-linear behavior of the DCSS devices. The coupling of motion along $\mathrm{x}$ and $\mathrm{y}$ directions is given by the bi-axial interaction modeling of the force response of the isolation system [1].

\section{CASE STUDY}

Given the parametric formulation of the dynamic system shown above, it is possible to analyze different structural layouts under a selected bidirectional seismic event, accounting for randomly distributed curves for the cycling effect.

In the present work, the Irpinia earthquake November $23^{\text {rd }} 1980$ has been considered, with both the $\mathrm{x}$ and $\mathrm{y}$ components acting simultaneously. In addition, both the $\mathrm{x}$ and $\mathrm{y}$ recordings have been scaled with a scale factor equal to 1,4 in order to achieve a displacement demand more comparable to the design displacement of the modeled device $(0,2 \mathrm{~m})$. A relatively small scaling factor has been chosen in order not to obtain unrealistic ground acceleration time histories.

In Figure 9 the both the $\mathrm{x}$ and $\mathrm{y}$ components of the chosen seismic event are reported.
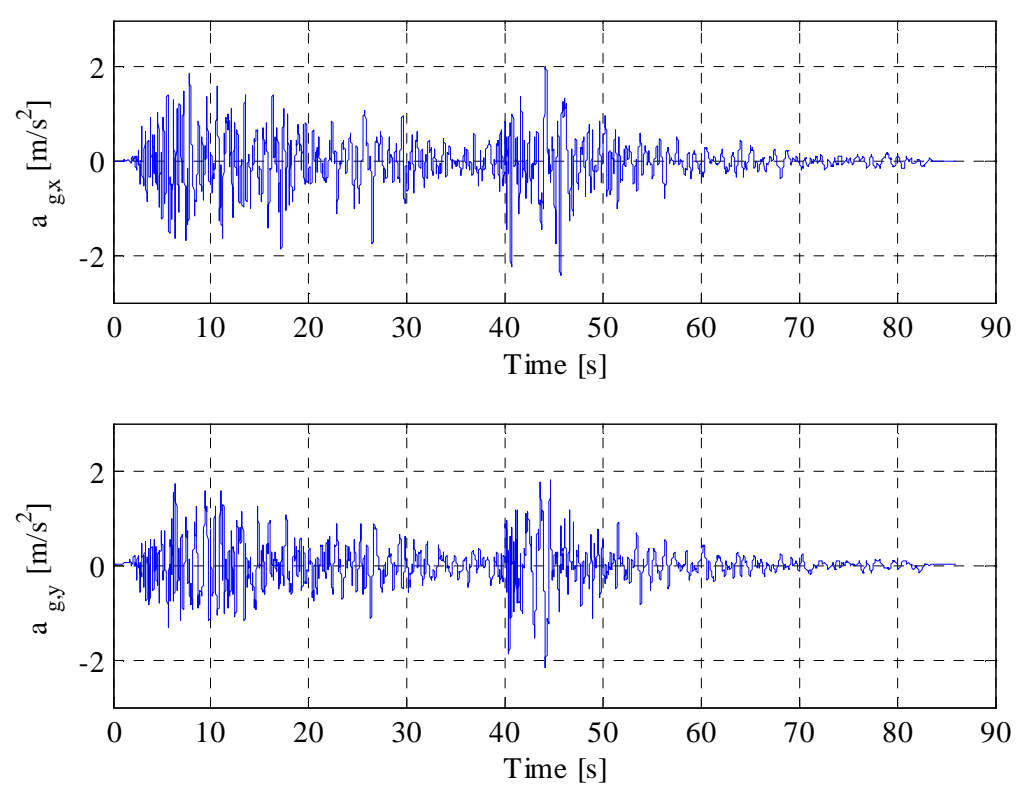

Figure 9: Irpinia earthquake: scaled $\mathrm{x}$ and y components.

Hence, buildings with five and seven floors have been considered, and for both of these typologies, three different fundamental periods have been assumed, as summarized in Table 2 . Since the isolation system is modeled by means of an equivalent device, which implies that 
each isolator is averagely loaded with the same vertical load, eq.(13) can be obtained. Given the number of isolators $\mathrm{N}_{\mathrm{I}}$ and the single average vertical load $\mathrm{W}$ :

$$
W=\frac{W_{t o t}}{N_{I}}=\frac{g\left(M_{P}+M_{B}\right)}{N_{I}}=\frac{g M_{P}\left(1+M_{B} / M_{P}\right)}{N_{I}}=\frac{g M_{P}(1+r)}{N_{I}}
$$

Thus, the single average vertical load $\mathrm{W}$ of the devices is a function of the mass of the isolated slab $M_{P}$, the mass ratio $r$ and the number of devices $\mathrm{N}_{\mathrm{I}}$.

Concerning the mass ratio $\mathrm{r}$, it can be seen as a direct function of the number of floors $\mathrm{N}_{\mathrm{F}}$ (eq.(14)):

$$
r=\frac{M_{B}}{M_{P}}=\frac{m \cdot N_{F}}{M_{P}}=\left(\frac{m}{M_{P}}\right) \cdot N_{F}
$$

In real applications the seismic mass per unit area of one floor is averagely equal to 1,0 ton $/ \mathrm{m}^{2}$, considering a concrete frame structure, external and internal masonry infills, a common structural technology of concrete and hollow-clay-tile floor system and 30\% of the live load relative to residential buildings [9]. Whereas, concerning the isolated slab, a previous work has shown that a typical thickness of the reinforced concrete slab laid on the isolation level is equal to $0,5 \mathrm{~m}$ [1], with a consequent value of mass per unit area equal to $1,25 \mathrm{ton} / \mathrm{m}^{2}$. According to these mass density values for both the building floor and the isolated mass, the mass ratio $r$ can be considered as $80 \%$ of the number of floors of the building. The value of the single average vertical load of the device for each case has been computed simulating a real case study: considering a grid of isolators made up of 10x5 DCSS devices (50 isolators), with $6 \mathrm{~m}$ span along both directions and assuming the thickness of the isolated slab equal to $0,5 \mathrm{~m}$ the values listed in Table 2 have been obtained: it can be noted that such values are comparable to the design vertical load values of the chosen isolator technology (about 2500 $\mathrm{kN})$.

\begin{tabular}{llll}
\hline $\mathrm{N}_{\mathrm{F}}[\#]$ & $\mathrm{T}_{\mathrm{s}}[\mathrm{s}]$ & $\mathrm{r}[\#]$ & $\mathrm{W}[\mathrm{kN}]$ \\
\hline 5 & 0,50 & 4,0 & 1500 \\
5 & 0,75 & 4,0 & 1500 \\
5 & 1,00 & 4,0 & 1500 \\
7 & 0,50 & 5,6 & 2000 \\
7 & 0,75 & 5,6 & 2000 \\
7 & 1,00 & 5,6 & 2000 \\
\hline
\end{tabular}

Table 2: Parameters of the considered structural layouts.

For all the structural layouts listed above, 500 values of the parameter $b$ have been randomly extracted using a numerical simulator which has a uniform distribution, given a variation range within $\pm 100 \%$ of the mean value of the parameter; thus the total number of performed analyses is equal to 3000 .

\section{ANALYSES RESULTS}

In the followings results are shown for all the structural layouts, as a comparison between neglecting rather than accounting for the cycling effect: precisely, since a bidirectional seismic event has been considered, all the peak vectorial response quantities of the structural sys- 
tem have been computed, that is displacements, absolute accelerations and interstorey shear forces. In all the next figures all the response curves of all the performed analyses are reported, together with the reference case curve, that is without accounting for the cycling effect, and with the mean plus and minus the standard deviation curves. Moreover, for each storey the ratio between the mean, maximum and minimum response parameter with respect to the reference case has been evaluated and shown in the graphs.

In Figure 10 and Figure 11 the results in terms of maximum vectorial displacement for all levels are reported, considering five and seven floors respectively.
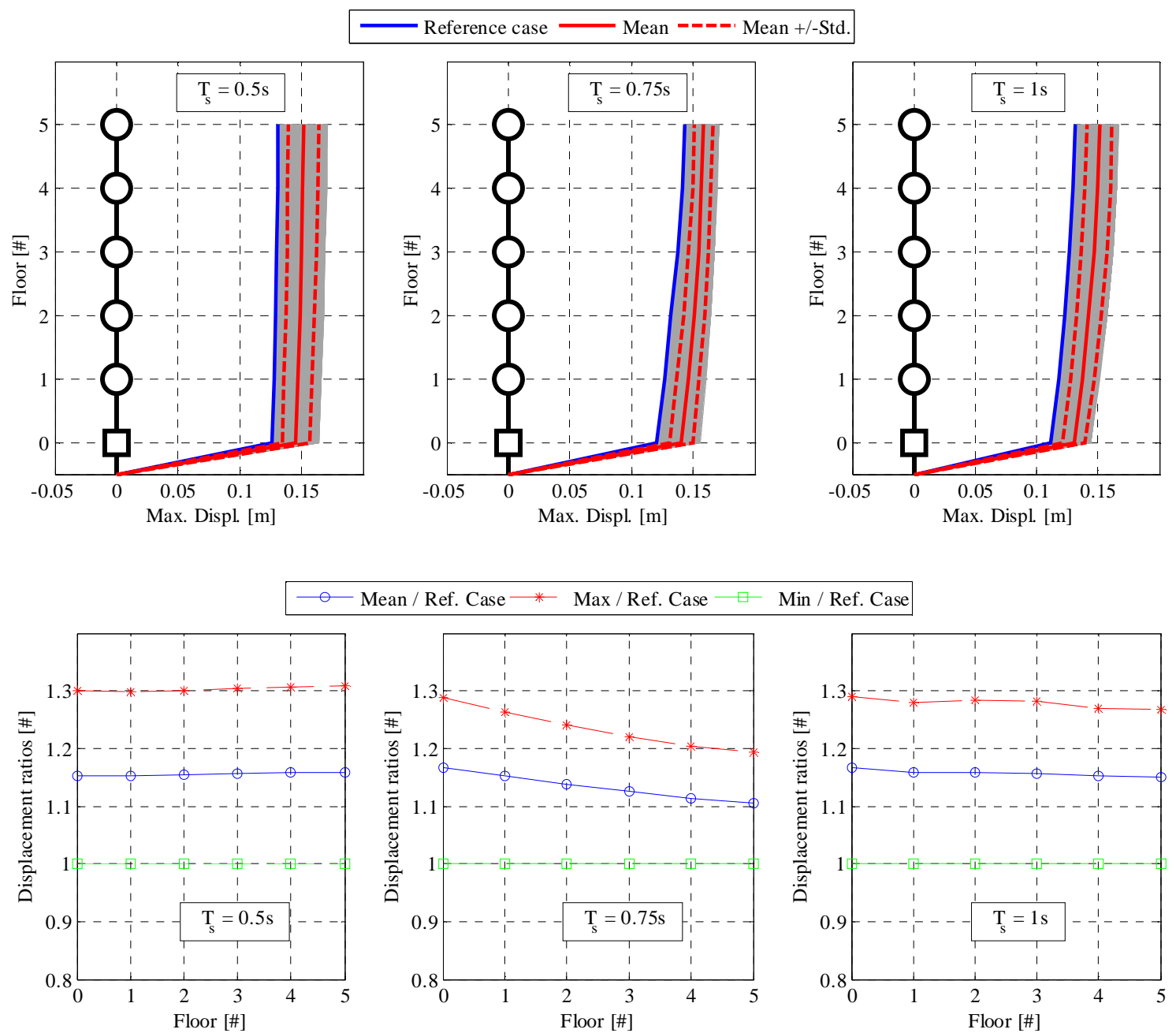

Figure 10: Displacement response: deformed shapes (up) and displacement ratios (down) for 5 storey building. 

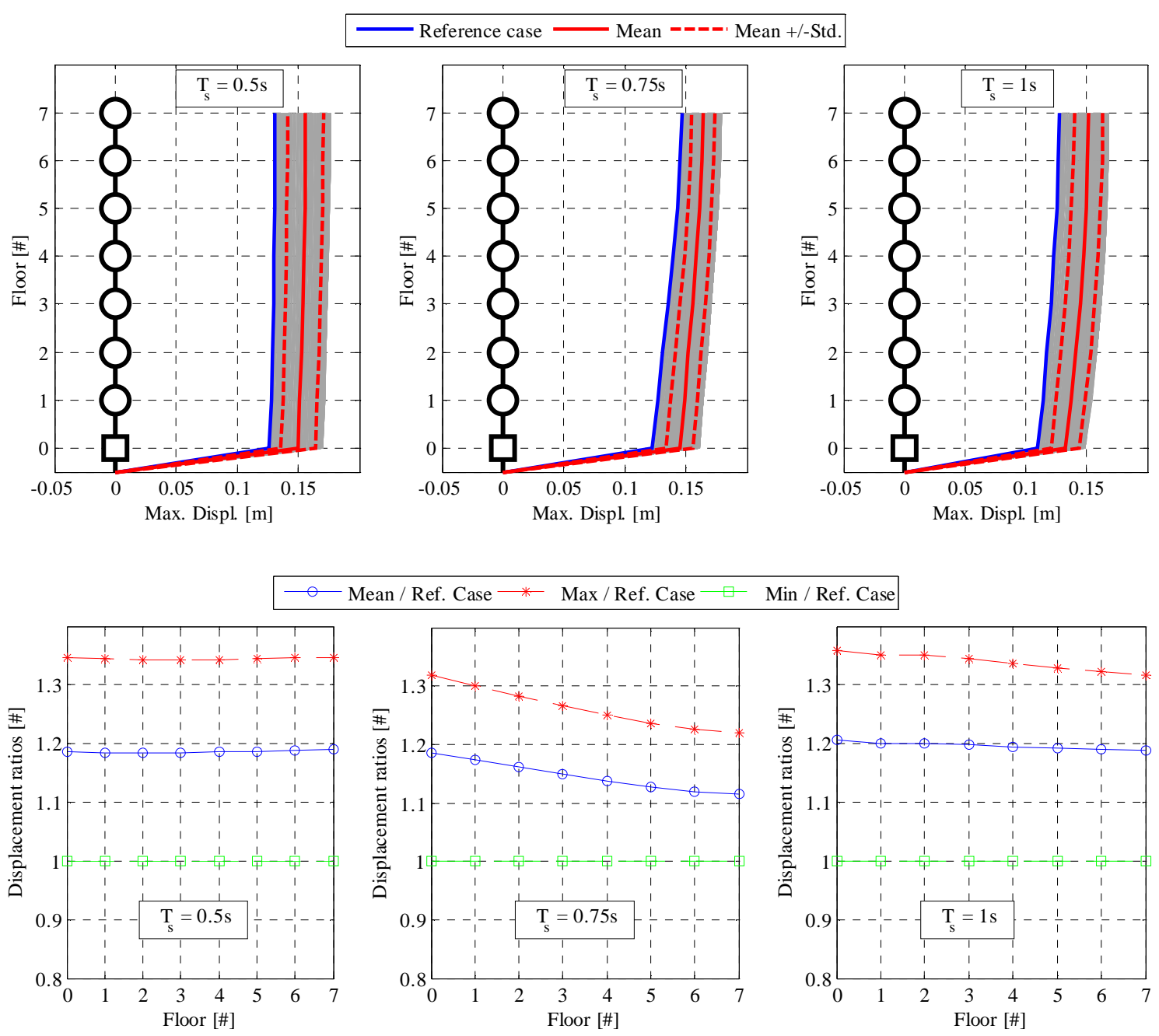

Figure 11: Displacement response: deformed shapes (up) and displacement ratios (down) for 7 storey building.

Results show that, for both the building typologies (5 and 7 stories) the presented model of the cycling effect of DCSS devices strongly influences the displacement response of an isolated system: it can be noted that the displacement demand at the isolation level increases up to $35 \%$ more than the reference case in the worst cases and the mean value is averagely $20 \%$ more; the graphs showing the displacement ratios underline that accounting for the cycling effect, the displacement demand is always higher with respect to the reference case for all the floors (the minimum ratio is equal to 1 ); for $0,75 \mathrm{~s}$ period, considering both 5 and 7 storey buildings, the displacement ratios slightly decrease at the highest levels, whereas in the other cases they are rather constant.

Then, in Figure 12 and Figure 13 the results in terms of maximum vectorial absolute acceleration at all levels are reported for both the five and seven floors layouts. 

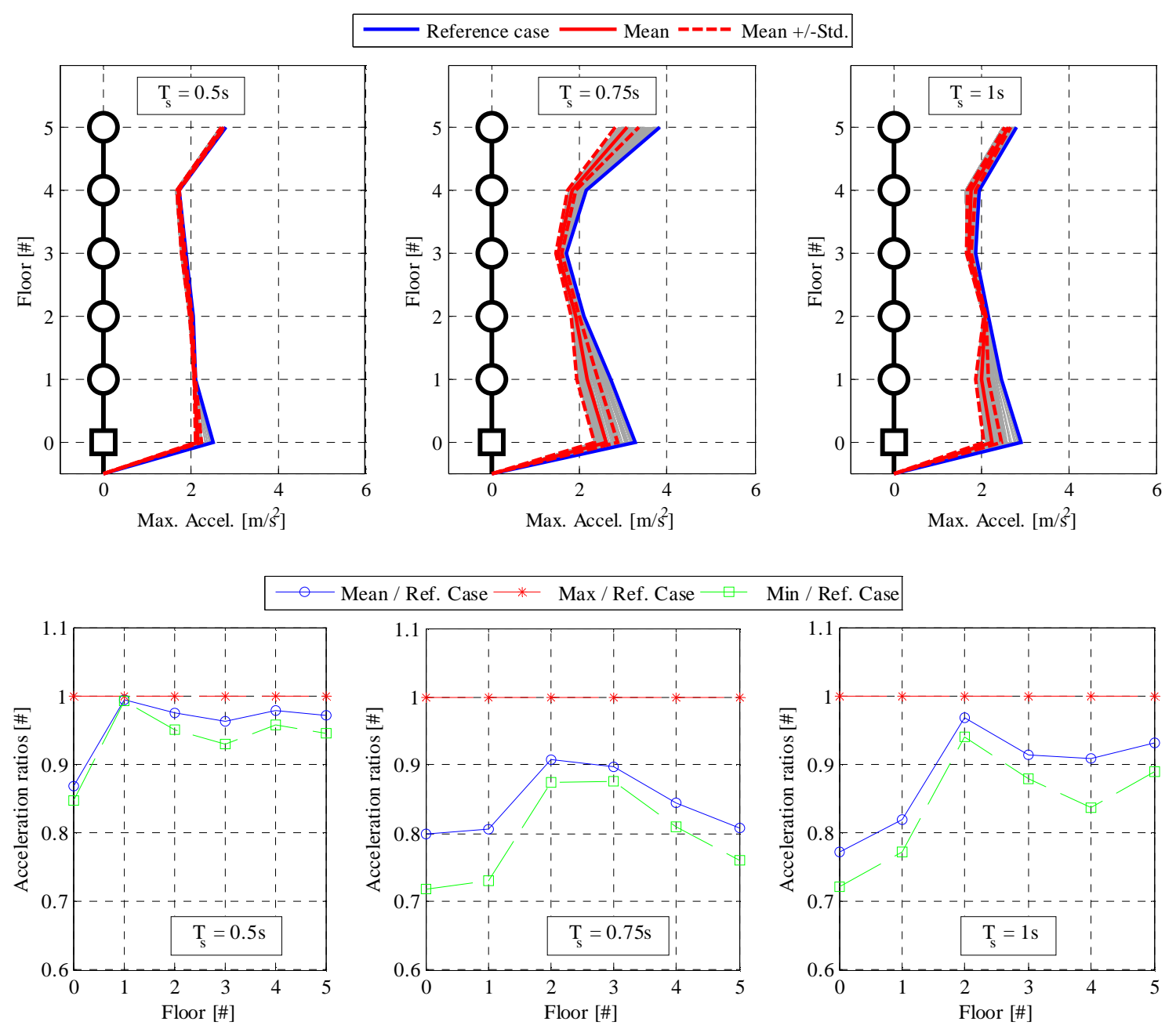

Figure 12: Acceleration response: acceleration profiles (up) and acceleration ratios (down) for 5 storey building.

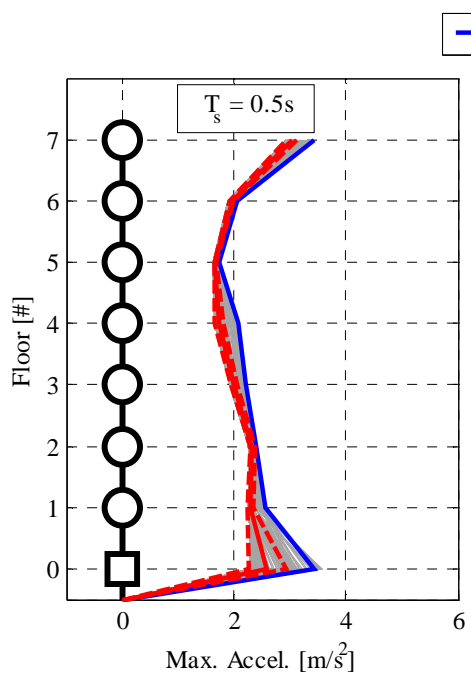

Reference case $\longrightarrow$ Mean -ーー- Mean +/-Std.
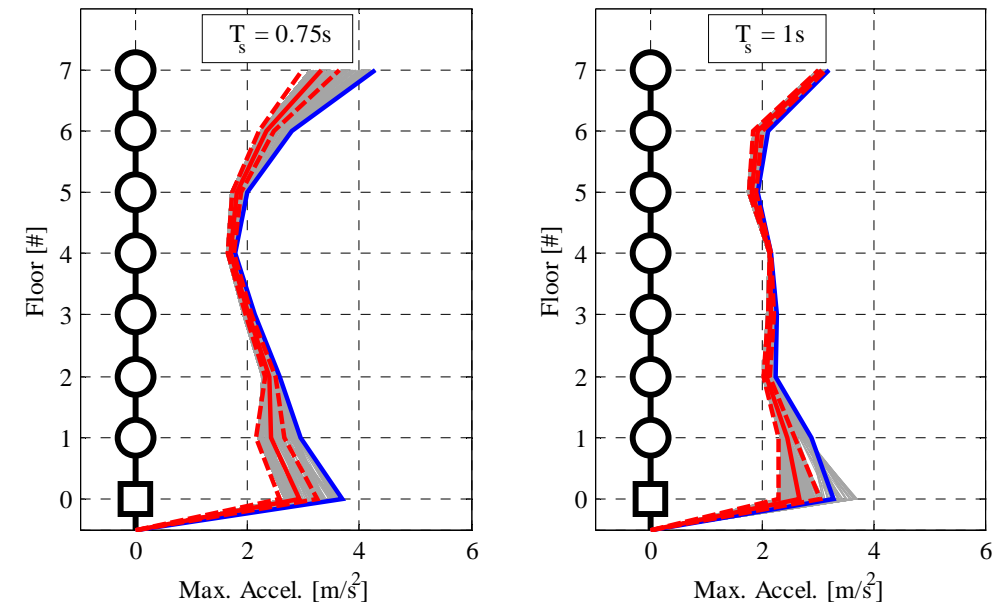

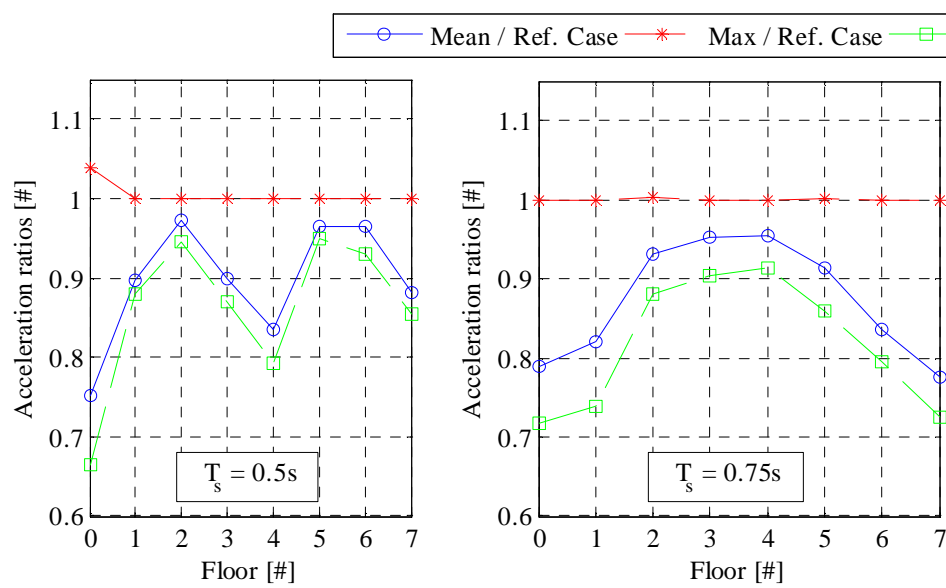

Min / Ref. Case

Figure 13: Acceleration response: acceleration profiles (up) and acceleration ratios (down) for 7 storey building.

For the 5 storey building the acceleration ratios of the maximum values are equal to 1 in all cases: this means that the cycling effect always reduces the absolute acceleration at all levels; nevertheless, for the 7 storey building the maximum value at the isolation level (level 0) is higher compared to the reference case, for structural periods equal to $0,5 \mathrm{~s}$ and $1,0 \mathrm{~s}$. Generally, the acceleration response significantly decreases just above the isolation level and at the last floors of the structure, assuming in the middle more comparable values to the reference case.

Finally, in Figure 14 and Figure 15 the results in terms maximum vectorial interstorey shear, normalized with respect to the total weight of the isolated structure, at all levels are reported for both the five and seven floors layouts. To compute the normalized shears for the building $\mathrm{V}_{\mathrm{B}, \mathrm{i}}$, at each storey the maximum vectorial drift $\mathrm{D}_{\mathrm{B}, \mathrm{i}}$ has been computed, computing thus the shear according to eq.(15); for the i-th floor:

$$
V_{B, i}=\frac{k D_{B, i}}{W_{t o t}}=\frac{k D_{B, i}}{m g N_{F}\left(1+\frac{1}{r}\right)}=\frac{\omega_{s}^{* 2} \cdot D_{B, i}}{g N_{F}\left(1+\frac{1}{r}\right)}
$$

Whereas for the isolation level, the normalized shear is given by eq.(11), divided by the expression of the total weight.

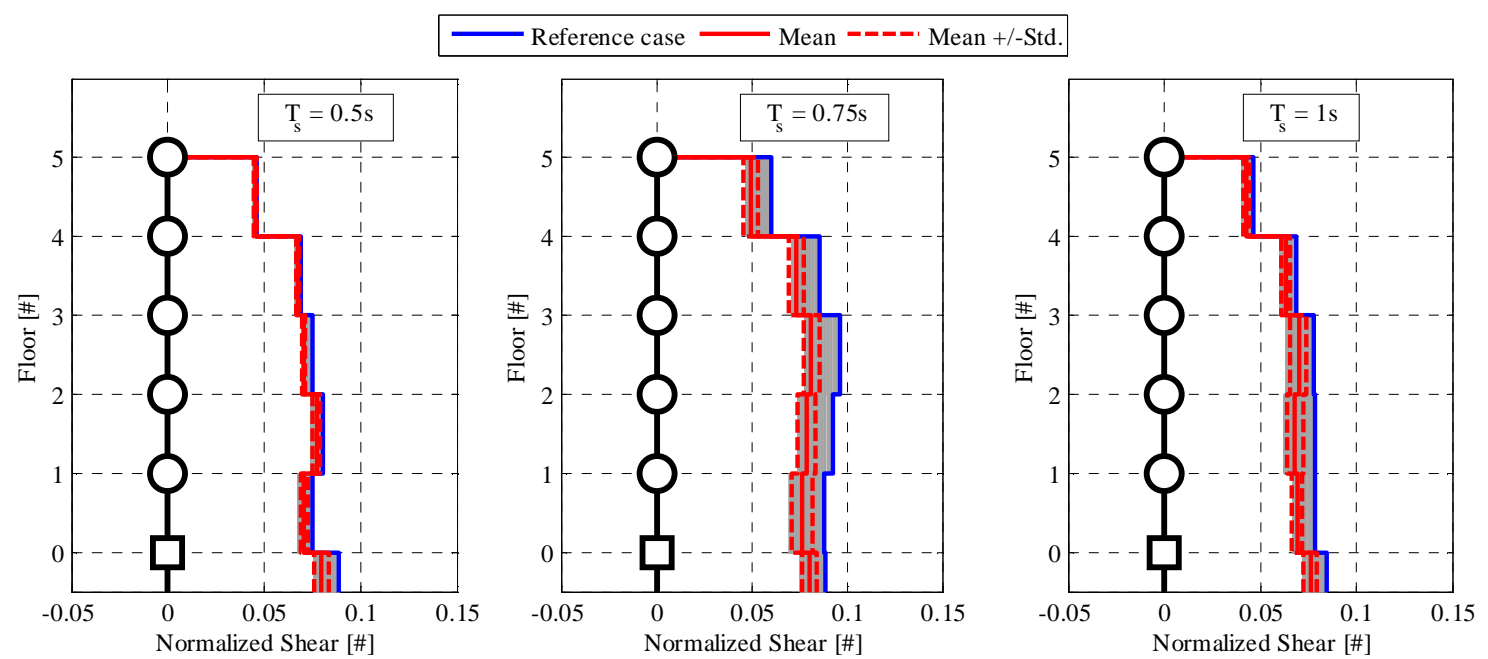



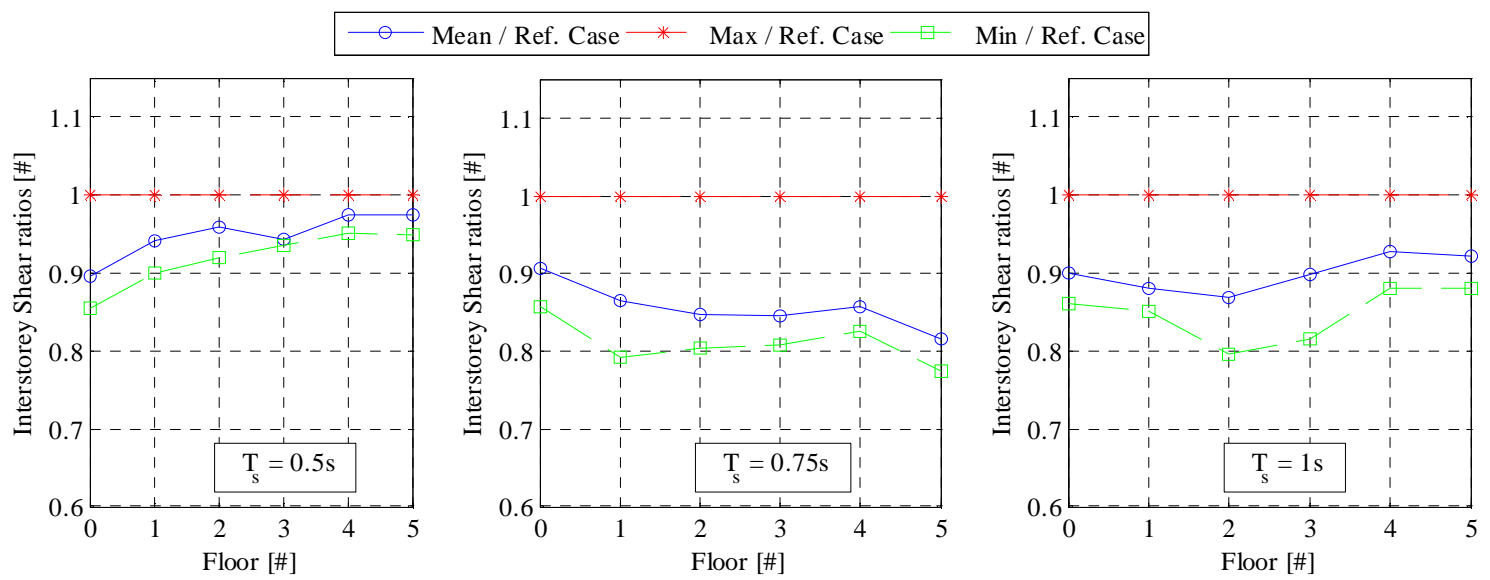

Figure 14: Shear response: Shear profiles (up) and shear ratios (down) for 5 storey building.

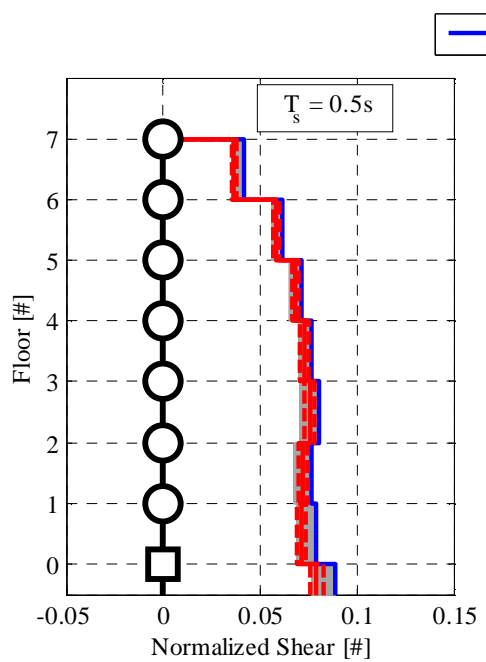

Reference case $\longrightarrow$ Mean ---- Mean +/-Std
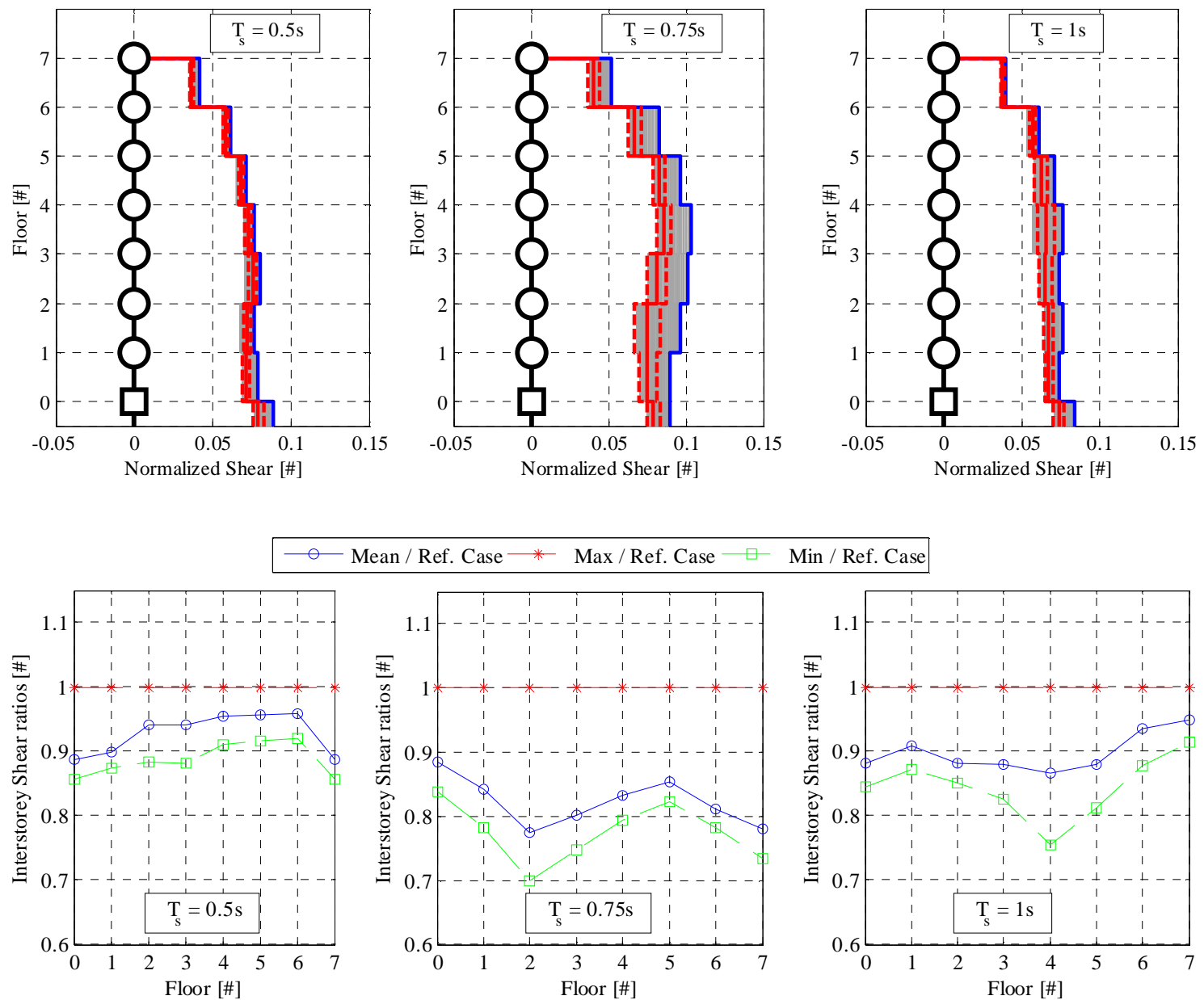

Min / Ref. Case

Figure 15: Shear response: Shear profiles (up) and shear ratios (down) for 7 storey building.

Also for the shear response, the reference case represents the upper bound of all the analyses performed accounting for the cycling effect. It can be noted that the mean and minimum values for all the stories are very close: this implies that also with a slight decreasing behavior 
of the friction coefficient due to the cycling effect, the shear response for each level significantly decreases. The highest variation for the 5 storey building reaches $-20 \%$ for both structural periods of $0,75 \mathrm{~s}$ and $1,0 \mathrm{~s}$, and $-30 \%$ for the structural period $0,75 \mathrm{~s}$.

\section{CONCLUSIONS AND FUTURE DEVELOPMENTS}

In the present endeavor a wide numerical campaign has been carried out in order to evaluate the variation of the peak response quantities of a structural system seismically isolated with DCSS devices due to the friction coefficient decay, caused by the cycling effect. Particularly, a new dynamic model for a MDOF system is presented, which does not depend on the mass of the structure. The considered structures consist of multy-storey buildings ( 5 and 7 stories) with different fundamental periods $(0,5 \mathrm{~s}-0,75 \mathrm{~s}-1,0 \mathrm{~s})$, isolated by means of a reinforced concrete slab, laid on a grid of DCSS isolators. Since all the structural layout are supposed to correspond to large plan development buildings, it has been possible to model the isolation system using an equivalent DCSS device: this implies that all the isolators can be considered with the same average vertical load, directly equal to the total weight of the whole isolated structure divided by the number of installed devices. The constitutive law of the isolation system has been returned by the summation of the recentering and the frictional forces: the former is modeled with a linear spring with a stiffness coefficient given by the ratio between the applied vertical load and the equivalent radius of curvature, whereas the latter is returned by a frictional model which accounts for bi-axial interaction of the directions of motion. Concerning the friction coefficient, it has been assumed as a constant function with respect to both sliding velocity and vertical load, in order to evaluate the influences of the cycling effect only: this has been modeled by means of randomly extracted decay curves, which expresses a decay multiplication factor as a function of the dissipated energy of a single isolator. In order to compute the dissipated energy for a single device, in terms of the integral of the force-displacement law, it has been necessary to define the single average vertical load, simulating a real case: thus, two different values have been considered, for 5 and 7 storey buildings respectively $(1500 \mathrm{kN}$ and $2000 \mathrm{kN})$.

Results have been computed in terms of maximum vectorial displacements, absolute accelerations and interstorey shears for all levels; moreover, a comparison to the reference case (no cycling effect) has been provided. Concerning the displacement response, the reference case is the lower bound of all the analyses in which the cycling effect is considered. At each storey, the friction coefficient decay leads to higher displacement demands, up to $35 \%$ more than the reference case in the worst condition. Such variability looks more significant at the isolation level and at the lower stories of the building, slightly decreasing for the higher floors. The opposite behavior has been found for both absolute acceleration and interstorey shears: in fact for such response parameters the reference case becomes the upper bound. Thus, the friction coefficient decay reduces the absolute acceleration values at all levels (particularly at the highest stories and just above the isolation system) and the shear profile (averagely the same variation along the building height).

This work has underlined that the cycling effect, in terms of friction coefficient decay, leads to non-negligible variations of the main response parameters. Thus a future development will be the definition and the calibration of a sophisticated model of the cycling effect, as a function of dissipated energy, sliding velocity and vertical load, thanks to the results of several unidirectional and bidirectional tests of full scale DCSS devices. 


\section{AKNOLEDGEMENTS}

Part of the current work has been carried out under the financial support Italian Civil Protection, within the framework of the Executive Project 2014-2016 (Project S2.0 - Seismic isolation and supplemental damping systems: evaluation of the seismic response of devices and structures).

\section{REFERENCES}

[1] M. Furinghetti, C. Casarotti, A. Pavese, Effects of bi-directional motion on a structural system isolated with DCSS devices with laying defects. 15th WCEE, World Conference on Earthquake Engineering, Lisbon, Portugal, September 24-28, 2012.

[2] C. Casarotti, M. Furinghetti, A. Pavese, Evaluation of response of an isolated system based on Double Curved Surface Slider. Computational method in Earthquake Engineering, 30, pp 397-416, 2013.

[3] M. Furinghetti, C. Casarotti, A. Pavese, Bi-directional experimental response of full scale dcss devices. 2ECEES, Second European Conference on Earthquake Engineering and Seismology, Istanbul, Turkey, August 25-29, 2014.

[4] G. Lomiento, N. Bonessio, G. Benzoni, Concave sliding isolator's performance under multi-directional excitation. Ingegneria Sismica, 30:3,17-32, 2013.

[5] G. Lomiento, N. Bonessio, G. Benzoni, Friction Model for Sliding Bearings under Seismic Excitation. Journal of Earthquake Engineering, 17, 1162-1191, 2013.

[6] G. Mosqueda, A.S. Whittaker, G.L. Fenves, Characterization and modeling of friction pendulum bearings subjected to multiple components of excitation. Journal of Structural Engineering, 130, 433-442, 2004.

[7] CEN, Comité Européen de Normalisation TC 340, European Code UNI EN 15129:2009 Anti-seismic devices. Brussels, 2009.

[8] F. Khoshnoudian, V.R. Hagdoust, Response of pure-friction sliding structures to three components of earthquake excitation considering variations in the coefficient of friction. Scientia Iranica, 16, 429-442, 2009.

[9] M. Dolce, D. Cardone, F. C. Ponzo, A. Di Cesare, Progetto di edifici con isolamento sismico, Seconda Edizione. IUSS Press, 2010.

[10] D. Fenz, M. C. Constantinou, Behaviour of the double concave friction pendulum bearing. Earthquake Engineering And Structural Dynamics, 35, 1403-1424, 2006.

[11] A. K. Chopra, Dynamics of Structures Theory and Applications to Earthquake Engineering. Prentice Hall, Upper Saddle River, NJ, 1995.

[12] S. Peloso, A. Pavese, C. Casarotti, Eucentre trees lab: Laboratory for training and research in earthquake engineering and seismology. Geotechnical, Geological and Earthquake Engineering, 20, 65-81, 2012.

[13] G.M. Calvi, A. Pavese, Conceptual design of isolation systems for bridge structures. Journal of Earthquake Engineering, 1, 193-218, 1997. 